\title{
Near-UV-induced absorbance change and photochemical decomposition of ergosterol in the plasma membrane of the yeast Saccharomyces cerevisiae
}

\author{
Shin-ichiro Arami, ${ }^{1}$ Megumi Hada² and Mikiro Tada'
}

Author for correspondence: Shin-ichiro Arami. Tel: +81862518310 . Fax: +81862540714 . e-mail: baiyou-1@cc.okayama-u.ac.jp

1 Division of Biological Function and Genetic Resources Science, Faculty of Agriculture, Okayama University, Tsushima-naka, Okayama 700, Japan

2 Department of Biology, Kobe University, Rokkodai, Nada-ku, 657 Kobe, Japan

\begin{abstract}
When cells of the yeast Saccharomyces cerevisiae were exposed to near-UV $(300-400 \mathrm{~nm})$, their absorption spectra changed slightly within the range 220-300 $\mathrm{nm}$ with increasing dosage. Difference spectra, calculated by subtracting the curve recorded in cells exposed to near-UV from the curve of unexposed cells, decreased with increasing dosage over a broad band with peaks at 272, 282 and $295 \mathrm{~nm}$ and a shoulder at $265 \mathrm{~nm}$. These peaks were in agreement with the absorption maxima of ergosterol, which is one of the major components of the plasma membrane of yeast. Near-UV radiation induced a simultaneous decrease in absorption spectra and reduction of ergosterol content in the plasma membrane. Photochemical decomposition of ergosterol by near-UV radiation was revealed in vivo, although ergosterol is generally known to be photoconverted to previtamin $D_{2}$ industrially by UV radiation in vitro. In order to remove photosensitizers, liposomes were prepared from phospholipids and glycolipids, with or without ergosterol from purified yeast plasma membranes. Liposomal ergosterol in the orientated state was photochemically decomposed by near-UV radiation but ergosterol in the disorientated state in a homogeneous solution was not. Near-UV radiation also induced a decrease in activity of membrane-bound ATPase. Dose-response curves for the reduction of ATPase activity were similar to that for decomposition of ergosterol, suggesting that near-UV caused membrane function damage.
\end{abstract}

Keywords: near-UV, ergosterol, membrane damage, plasma membrane, Saccharomyces cerevisiae

\section{INTRODUCTION}

It is well known that near-UV radiation induces inactivation of the cell and repression of cell growth and multiplication (Jagger, 1981). DNA damage accompanied by formation of pyrimidine dimers (Boyce $\&$ Howard-Flanders, 1964), DNA single-strand breaks (Rosenstein \& Ducore, 1983) and generation of activated oxygen species by photosensitizers (Piette et al., 1986 ) is directly induced by UV radiation and causes serious damage in all organisms. However, near-UV radiation results in little direct DNA damage, such as formation of pyrimidine dimers (Tyrrell, 1973).

Near-UV radiation clearly reduces some functions of the plasma membrane, such as active transport (Robb et al., 1978; Ascenzi \& Jagger, 1979; Sharma \& Jagger, 1981), ion transport (Siegel \& Corn, 1974) and its ability to act as a permeability barrier (Ito \& Ito, 1983). In our previous study, the dose-response curve for survival of yeast cells exposed to near-UV was similar to that for disruption of the permeability barrier and for uptake of amino acids, indicating that reduction of these membrane functions was related to inactivation of the cell (Arami et al., 1993). These phenomena suggest that the target for membrane damage by near-UV is a component $(\mathrm{s})$ within the plasma membrane and that photochemical alteration of the target may result in damage of membrane function, which plays an important role in normal intracellular activity.

The plasma membrane is composed mainly of proteins and lipids. The function of the plasma membrane is maintained and regulated by the delicate balance of 
constituents in the membrane. Changes in the constituents disrupt this balance, inducing reduction of various membrane functions and finally leading to inactivation of the cell. In this study, we examine a constituent(s) in the plasma membrane altered by nearUV. When a cell suspension and membrane fraction of the yeast Saccharomyces cerevisiae were exposed to near-UV at various dosages, absorbance changes were detected as difference spectra resulting in a decrease over a broad band with peaks at 272, 282 and $295 \mathrm{~nm}$ and a shoulder at $265 \mathrm{~nm}$. It was indicated that the decrease in absorbance resulted from photochemical decomposition of ergosterol in the plasma membrane.

\section{METHODS}

Culture and irradiation procedure. Saccharomyces cerevisiae IS66-4C $\alpha$ was grown in the dark at $26^{\circ} \mathrm{C}$ for $20 \mathrm{~h}$ in YPD medium containing $1 \%$ yeast extract, $2 \%$ Bactopeptone and $2 \%$ glucose $(\mathrm{w} / \mathrm{v})$ with continuous shaking at 125 r.p.m. until in stationary phase. Yeast cells were harvested by centrifugation and washed twice with distilled water. The cells were suspended in distilled water to a final concentration of $0.13 \mathrm{mg}$ dry cell weight $\mathrm{ml}^{-1}$ and pipetted into quartz cuvettes. NearUV irradiation was carried out as described previously by Tada \& Shiroishi (1982) with slight modifications. Cell suspensions were exposed to near-UV emitted from a fluorescent lamp (National FL20S BL-B; emission wavelength $300-400 \mathrm{~nm}$ ) with continuous stirring and cooled with ice. Where nitrogen gas and air were bubbled through during irradiation, the cells were suspended in degassed distilled water which was prepared by sonication under reduced pressure. The flow rate of gases was $70 \mathrm{ml} \mathrm{min}{ }^{-1}$. Absorbance changes in cell suspensions exposed to near-UV at various dosages were measured with an automatic spectrophotometer (Shimadzu UV-3000). In order to detect slight changes of absorption spectra, difference spectra were calculated by subtracting the curve recorded in irradiated cells from the curve of intact control cells.

Ascorbate and $\alpha$-tocopherol were used as radical scavengers. $\alpha$-Tocopherol was dissolved in tetrahydrofuran/DMSO $(1: 1$, $\mathrm{v} / \mathrm{v}$ ) and added to the yeast suspension at a final concentration of $1 \%$. After incubation at $30^{\circ} \mathrm{C}$ for $2 \mathrm{~h}$ in the dark, yeast cells were harvested by centrifugation. During irradiation by near$\mathrm{UV}$, yeast cells were suspended in distilled water containing $10 \mathrm{mM}$ ascorbate at the final density described above.

Preparation of the plasma membrane. Yeast cells were suspended in $0 \cdot 1 \mathrm{M}$ Tris $/ \mathrm{HCl}$ buffer $(\mathrm{pH} 7 \cdot 2)$ containing $10 \mathrm{mM}$ EDTA, $1 \cdot 2 \mathrm{M}$ sorbitol and $1 \mathrm{mg}$ zymolyase $\mathrm{ml}^{-1}$. The reaction mixture was incubated at $30^{\circ} \mathrm{C}$ for $2 \mathrm{~h}$ and protoplasts were formed. After washing twice with the same buffer lacking zymolyase, protoplasts were burst by suspension in $0 \cdot 1 \mathrm{M}$ Tris/HCl buffer ( $\mathrm{pH} 7 \cdot 4$ ). Impurities were removed by centrifugation at $2300 \mathrm{~g}$ for $5 \mathrm{~min}$ at $4{ }^{\circ} \mathrm{C}$. The microsomal fraction was precipitated by centrifugation at $12000 \mathrm{~g}$ for $30 \mathrm{~min}$ at $4{ }^{\circ} \mathrm{C}$. After the precipitate was washed twice with the latter buffer, the plasma membrane was collected using a density gradient with sucrose at $100000 \mathrm{~g}$ for $60 \mathrm{~min}$ at $4{ }^{\circ} \mathrm{C}$. The layer containing the plasma membrane was determined by assay of $\mathrm{Mg}^{2+}$-ATPase, which was used as a marker enzyme. For determination of ATPase activity, the plasma membrane was suspended in a reaction mixture containing $50 \mathrm{mM} \mathrm{Tris} / \mathrm{HCl}$ ( $\mathrm{pH} 7 \cdot 8$ ), $3 \mathrm{mM} \mathrm{MgCl}_{2}$ and $2 \mathrm{mM}$ ATP to a final concentration of $1 \mathrm{mg}$ protein $\mathrm{ml}^{-1}$. After incubation at $30^{\circ} \mathrm{C}$ for $10 \mathrm{~min}$, the phosphate released from ATP was determined as described by Fiske \& Subbarow (1925). This layer was not contaminated by mitochondria since the ATPase activity was not inhibited in the presence of sodium azide.

Determination of ergosterol content. Ergosterol content was determined by the method of Arnezeder et al. (1989) with slight modifications. Samples exposed to near-UV were refluxed for $1 \mathrm{~h}$ in $5 \mathrm{ml} 90 \%(\mathrm{v} / \mathrm{v})$ ethanol containing 7dehydrocholesterol used as an internal standard. After addition of $5 \mathrm{ml} 50 \%(\mathrm{v} / \mathrm{v})$ ethanol, the sample was filtered through a cellulose acetate filter (pore size $0.45 \mu \mathrm{m}$ ). The filtrate was treated with a SEP-PACK C-18 cartridge and ergosterol was dissolved with 2-propanol. The solution containing ergosterol was analysed with HPLC apparatus attached to a Nucleosil ODS column $(4.5 \times 150 \mathrm{~mm} ; 5 \mu \mathrm{m}$ particles). Using methanol/ethanol/water $(86: 10: 4$, by vol.) as the mobile phase, the solution was pumped through the column at a flow rate of $1.5 \mathrm{ml} \mathrm{min}^{-1}$. Ergosterol and 7 dehydrocholesterol were monitored by the $A_{280}$.

Preparation of liposomes. The total lipids from plasma membranes of yeast cells were extracted as described by Allen \& Good (1971). Plasma membranes were suspended in chloroform/methanol $(1: 2, \mathrm{v} / \mathrm{v})$ and the suspension was vigorously stirred. After centrifugation at $1000 \mathrm{~g}$ for $5 \mathrm{~min}$, the residue was re-extracted with chloroform/methanol $(1: 1$, $\mathrm{v} / \mathrm{v}$ ). The chloroform layer was concentrated by a rotary vacuum evaporator. Total lipids were fractionated using silica gel C-100 column chromatography $(13 \times 2 \cdot 0 \mathrm{~cm})$ developing in the order chloroform, acetone and methanol, separating neutral lipids, glycolipids and phospholipids. Compositions of glycolipids and phospholipids were determined by twodimensional TLC; the first development was with chloroform/methanol/water $(65: 25: 4$, by vol.) and the second development was with chloroform/methanol/ ammonium hydroxide $(63: 35: 5$, by vol.).

Reconstructed liposomes were produced according to the method of Darszon et al. (1980). Fractions of glycolipids, phospholipids and commercial ergosterol were dissolved in a small amount of diethyl ether and transferred to an Erlenmeyer flask of $200 \mathrm{ml}$ capacity. After evaporation of the solvent in a stream of nitrogen, distilled sterilized water was gently poured into this flask. Large liposomes were produced after sealing with nitrogen and maintained at room temperature for $24 \mathrm{~h}$.

\section{RESULTS}

\section{Near-UV-induced absorbance change}

When yeast cell suspensions were exposed to near-UV at $10 \mathrm{~J} \mathrm{ml}^{-1}$, a slight change was observed in the absorption spectrum (Fig. 1a). In order to examine the detail of the spectral change, the difference spectra were calculated by subtracting spectra curves recorded in cells exposed to near-UV at various dosages from curves of intact cells. There was evidently a decrease over the broad band from 260 to $300 \mathrm{~nm}$ with increasing dosage and peaks were observed at 272, 282 and $295 \mathrm{~nm}$ (Fig. 1b). These three peaks were in excellent agreement with characteristic absorption maxima of ergosterol, which is one of the major components of the plasma membrane in fungi.

In the case of irradiation of the isolated plasma membrane, the difference spectra also had peaks at 272, 282 and $295 \mathrm{~nm}$ with a shoulder at $265 \mathrm{~nm}$ and were 

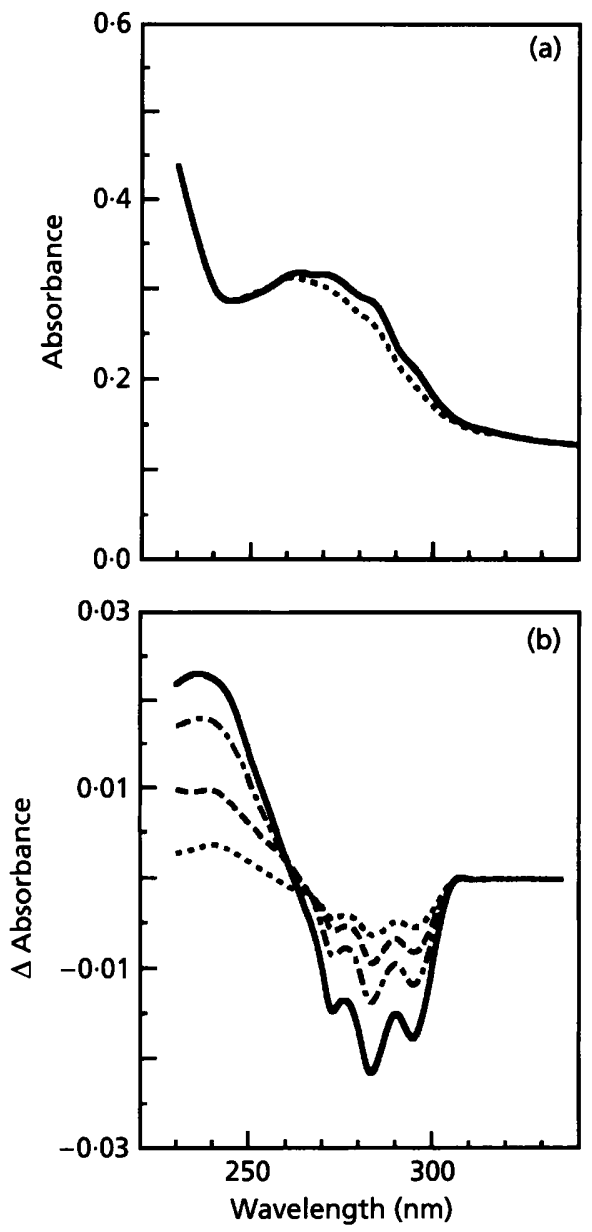

Fig. 1. Effects of near-UV irradiation on the absorbance spectrum of intact cells of the yeast $S$. cerevisiae. (a) Absorption spectra before (solid line) and after (dotted line) irradiation at $10 \mathrm{~J} \mathrm{ml}^{-1}$ under ice cooling with continuous stirring. Cells were suspended in distilled water to a final concentration of $0.13 \mathrm{mg}$ dry cell weight $\mathrm{ml}^{-1}$. (b) Difference spectra were calculated by subtracting the curve recorded in yeast cells exposed to nearUV at a dosage of $1.25(--), 2.5(-), 5.0(-)$ or $10(-)$ $\mathrm{J} \mathrm{ml}^{-1}$ from the curve of intact cells. Curves were derived from single sets of results and were reproducible in repeated experiments.

extremely similar to the peaks observed in the cell suspension (Fig. 2). Moreover, an isosbestic point was found at $260 \mathrm{~nm}$ on both spectra. However, the difference spectra of the cell wall and cytoplasmic fractions were not similar to the cell suspension (data not shown). These facts indicated that spectral changes in the yeast cell suspension due to near-UV radiation originated from a change in the membrane fraction. The wavelength of the peaks in each spectra agreed with theoretical peaks of ergosterol in homogeneous solution, although the relative intensity differed. Since decreases in $A_{282}$ occurred by altering the near-UV intensity and decreases were in direct proportion to the logarithms of the dosages in both cell suspension and the plasma membrane, the Bunsen-Roscoe reciprocity rule held under our experimental conditions.
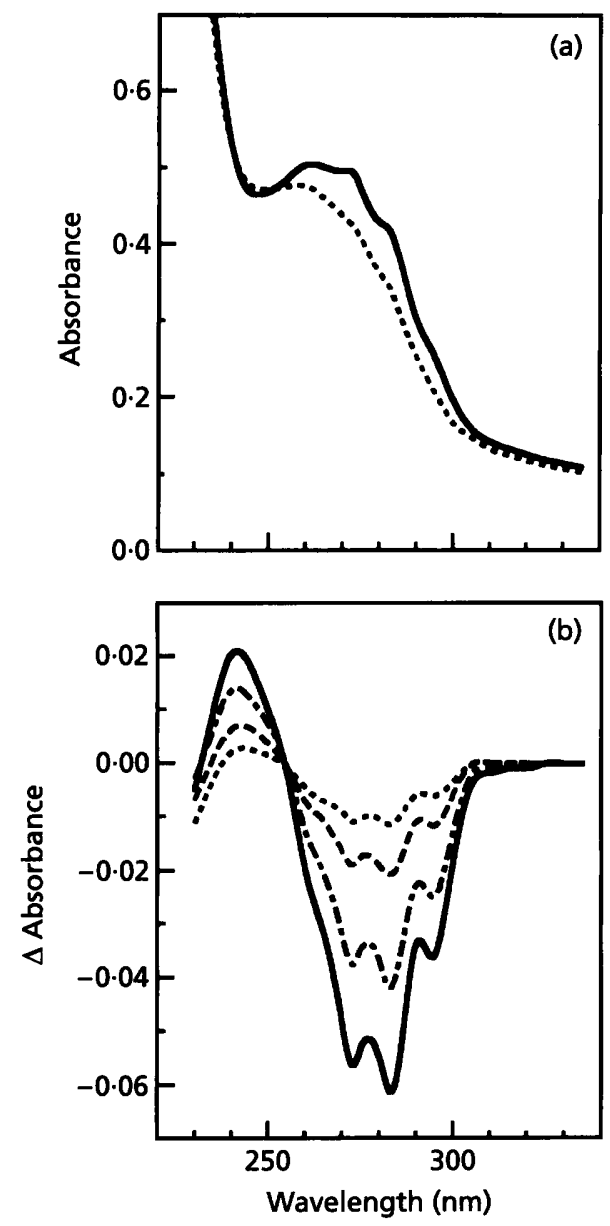

Fig. 2. Effects of near-UV irradiation on the absorbance spectrum in a membrane suspension prepared from yeast cells. (a) Absorption spectra before (solid line) and after (dotted line) irradiation at $10 \mathrm{~J} \mathrm{ml}^{-1}$. Plasma membranes were suspended in distilled water to a final concentration of $0.1 \mathrm{mg}$ protein $\mathrm{ml}^{-1}$. (b) Difference spectra were calculated by subtracting the curve recorded in the membrane exposed to near-UV at a dosage of $1.25(--), 2.5(-), 5.0(--)$ or $10(-) \mathrm{J} \mathrm{ml}^{-1}$ from the curves of the non-exposed membrane. Curves were derived from single sets of results and were reproducible in repeated experiments.

In order to examine whether near-UV-induced absorbance change depended on the oxygen concentration, suspensions of plasma membrane were exposed to nearUV with continuous bubbling of either nitrogen gas or air (Fig. 3). In samples with bubbled air, absorbance changes were similar to those in Fig. 2 but few changes were detected with bubbled nitrogen gas. These results suggested that absorbance changes were caused by photochemical decomposition of ergosterol dependent on oxygen coming from oxidative or peroxidative photolysis.

\section{Effect of near-UV radiation on ergosterol content}

After near-UV irradiation of cells and the plasma membrane, the ergosterol content was measured using HPLC. The content in both samples clearly decreased 


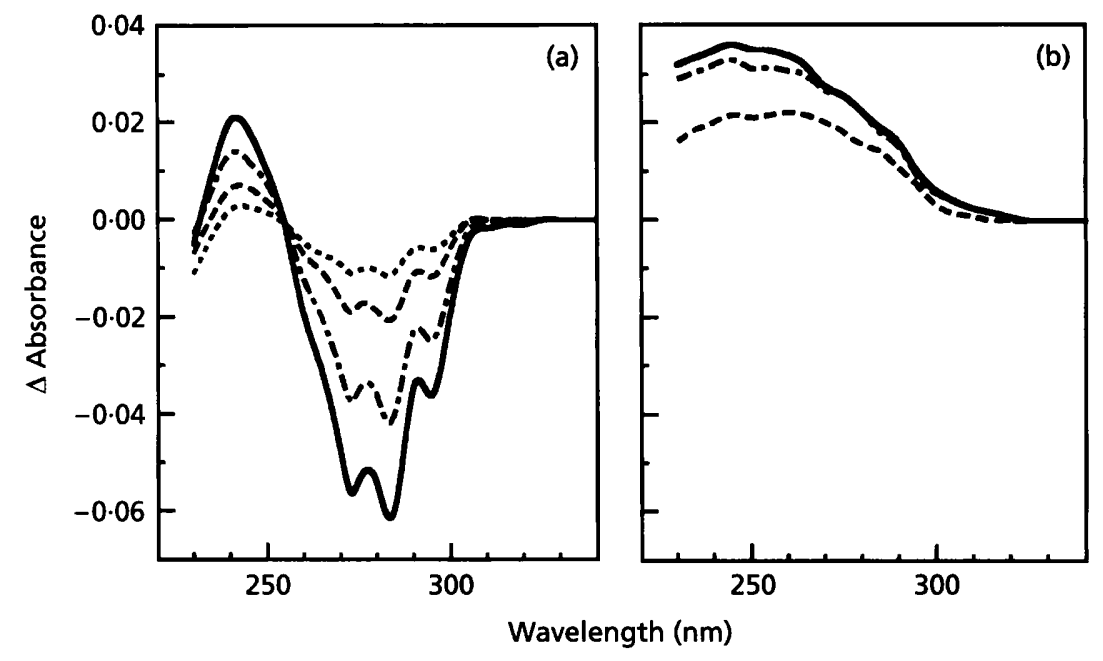

Fig. 3. Dependence on oxygen of the absorbance change in the plasma membrane of yeast. During near-UV irradiation of the membrane at a dosage of $1.25(-\infty), 2.5$ $(-), 5.0(--)$ or $10(-) \mathrm{J} \mathrm{ml}^{-1}$, air (a) or nitrogen gas (b) was bubbled into the suspension at a flow rate of $70 \mathrm{ml} \mathrm{min}^{-1}$ under ice cooling. Curves were derived from single sets of results and were reproducible in repeated experiments.

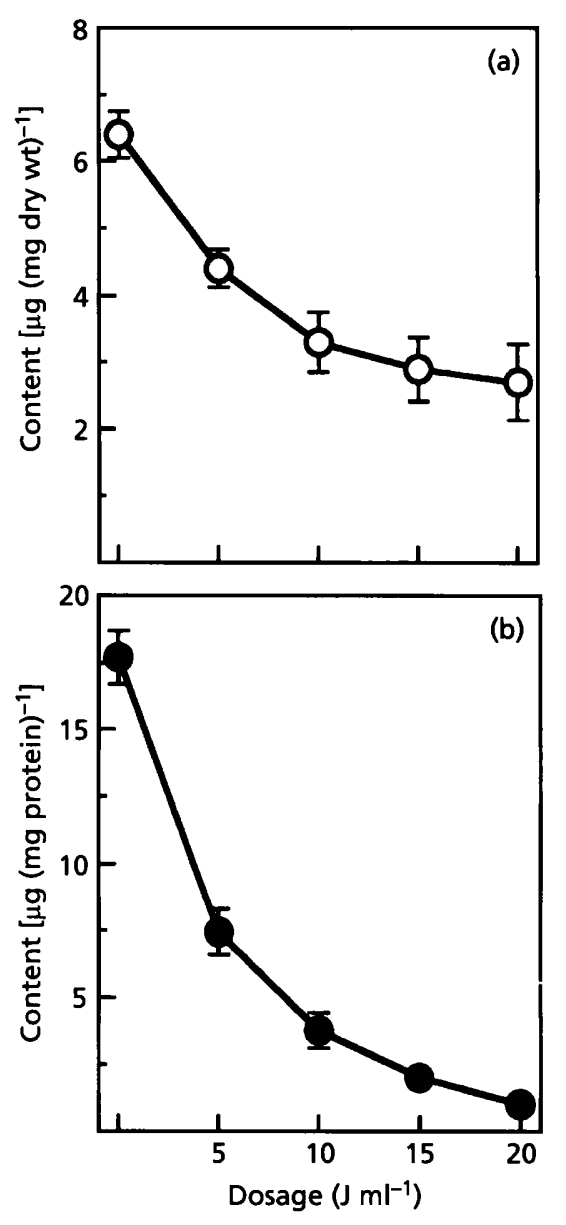

Fig. 4. Decrease in content of ergosterol in intact yeast cells (a) and plasma membrane (b) by near-UV irradiation. Irradiation conditions were the same as in Figs 1 and 2 . Each value represents the mean and standard error of results from three independent experiments.

with increasing dosage (Fig. 4). The relationship between near-UV-induced absorbance change and decrease in ergosterol content in intact cells and plasma

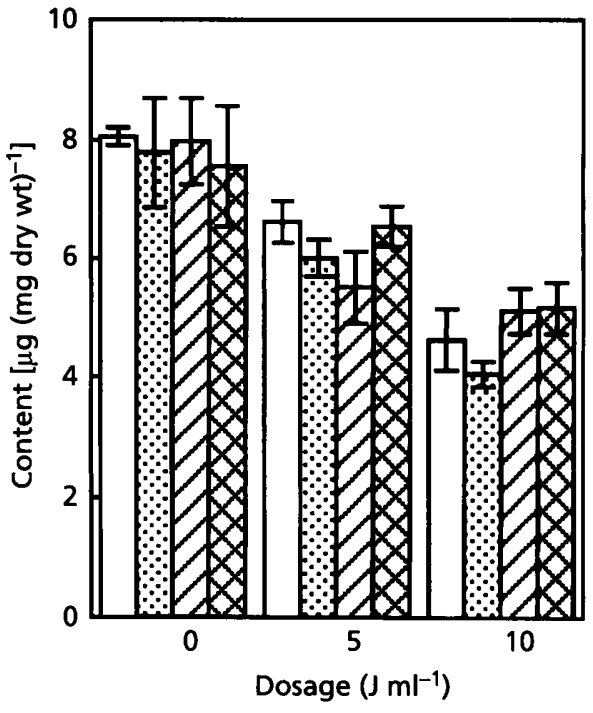

Fig. 5. Effects of radical scavengers on the decrease in ergosterol content in yeast cells by near-UV irradiation. $\alpha$-Tocopherol dissolved in tetrahydrofuran/DMSO was added to yeast suspensions at a final concentration of $1 \%$ and incubated at $30^{\circ} \mathrm{C}$ for $2 \mathrm{~h}$ in the dark. The yeast cells were exposed to nearUV with $\alpha$-tocopherol and ascorbate (open bar). After incubation in the presence of the solvent vehicle, cells were exposed with (dotted bar) or without (single-hatched bar) ascorbate. Untreated cells were exposed as a control (doublehatched bar). Irradiation conditions were the same as in Fig. 1. Each value represents the mean and standard error of results from three independent experiments.

membranes was examined. A decrease in $A_{282}$ was found to be directly proportional to the decomposition of ergosterol in the cell suspensions and plasma membrane, indicating that the absorbance change was reflected in a decreased ergosterol content. Yeast cells were then exposed to near-UV radiation in the presence of ascorbate and $\alpha$-tocopherol, which were used as radical scavengers (Fig. 5). Regardless of the presence of these scavengers, ergosterol content decreased with increasing dosage. This finding indicated that ergosterol was 

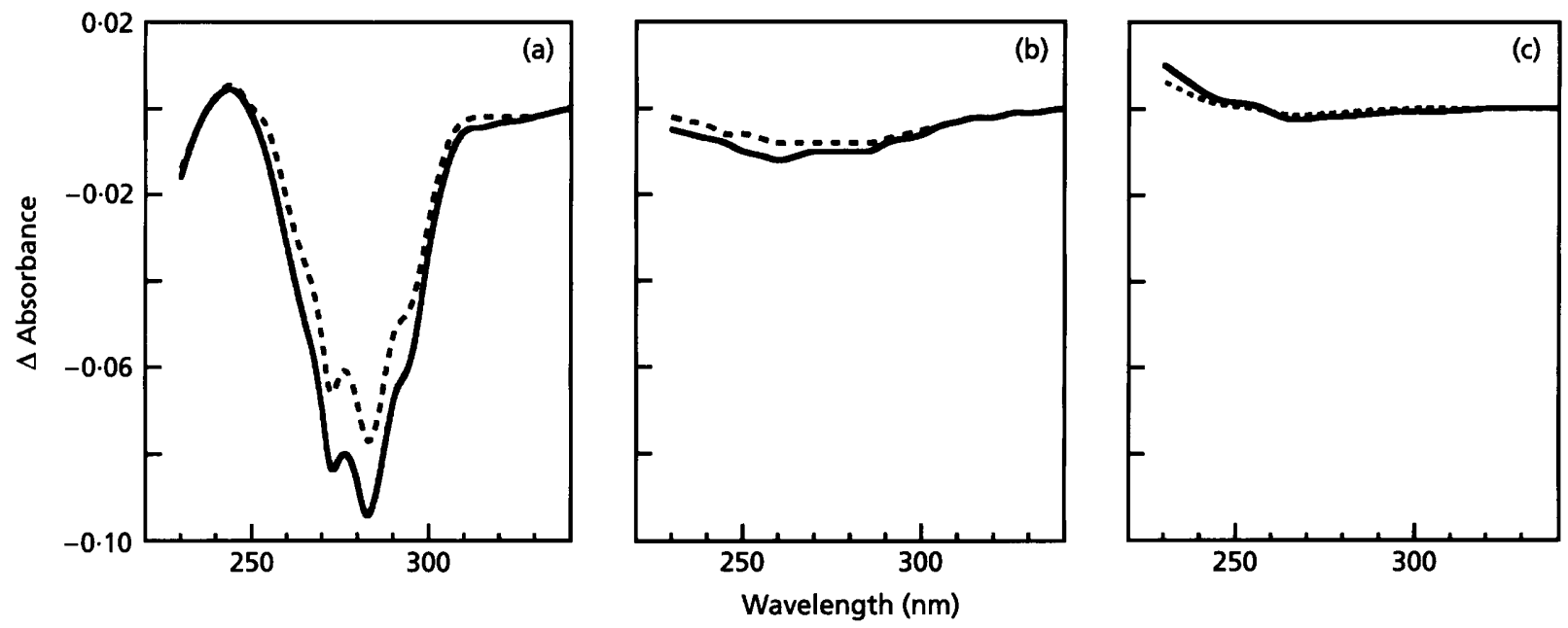

Fig. 6. Patterns of difference spectra of the orientated (a) and disorientated (b) state of ergosterol after near-UV irradiation. Liposomes were constructed with glycolipids and phospholipids extracted from plasma membranes of yeast in the presence (a) or absence (c) of ergosterol. An ethanol solution of ergosterol was used as the disorientated state (b). Each sample was exposed to near-UV at a dosage of 5.0 (dotted line) or 10.0 (solid line) $\mathrm{J} \mathrm{ml} \mathrm{ml}^{-1}$ under ice cooling. Curves were derived from single sets of results and were reproducible in repeated experiments.

directly photodecomposed by near-UV radiation without mediating radicals.

\section{Decomposition of liposomal ergosterol by near-UV}

It is well known that ergosterol and 7-dehydrocholesterol, which are used as starting compounds for production of vitamin $\mathrm{D}$, are difficult to photo-convert into previtamin D above the $300 \mathrm{~nm}$ wavelength (Braun et al., 1991). In spite of this fact, ergosterol was clearly decomposed by near-UV in this study. We measured absorbance changes of ergosterol due to near-UV radiation in the orientated and disorientated state. Photosensitizers generate activated oxygen species upon irradiation which cause widespread damage in various intracellular molecules. Therefore, we also prepared reconstructed liposomes to exclude the possibility that photodecomposition of ergosterol was mediated by photosensitizers.

When liposomes were constructed from phospholipids, glycolipids and ergosterol, then exposed to near-UV, the difference spectra drastically decreased with increasing dosage in a similar manner to the plasma membrane (Fig. 6a), although the spectra did not change in the liposome constructed without ergosterol (Fig. 6c). In the case of the disorientated state, a slight change similar to the pattern of the liposome without ergosterol was observed (Fig. 6b). In addition, the content of ergosterol apparently decreased in liposomes exposed to near-UV radiation but was constant in the ethanol solution (Fig. 7). During irradiation of liposomes with continuous bubbling of nitrogen gas, neither a decrease in absorption spectra nor a decrease in ergosterol content occurred (data not shown).

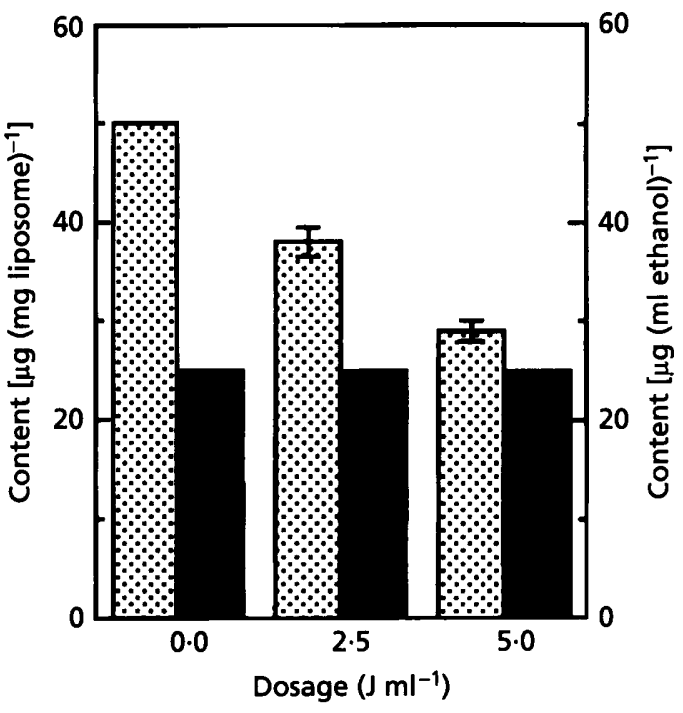

Fig. 7. Photochemical decomposition of liposomal (dotted bar) and homogeneous (closed bar) ergosterol after near-UV irradiation. Experimental conditions were the same as in Fig. 6. Each value represents the mean and standard error of results from three independent experiments.

\section{Near-UV-induced reduction of membrane-bound ATPase activity}

It is well known that the plasma membrane contains several varieties of ATPase which play important roles as ion pumps and antiports, and are essential for normal growth and maintenance of physiological activity in organisms. It was shown that near-UV radiation has an effect on ATPase activity and ergosterol content in the plasma membrane (Fig. 8). The ATPase activity was clearly reduced with increasing dosage, in parallel with 

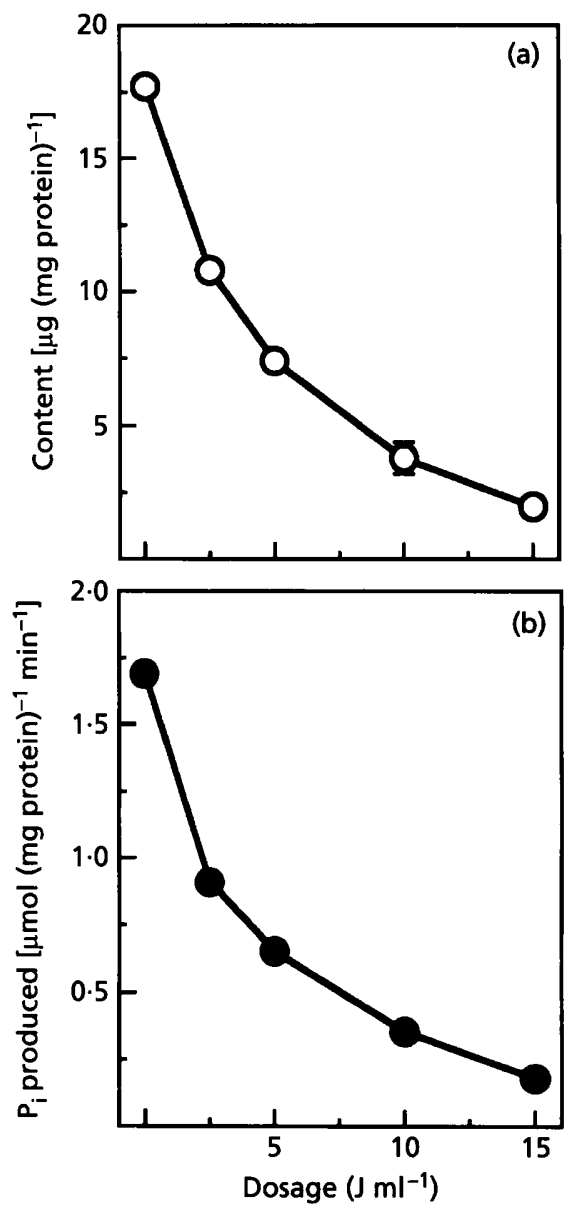

Fig. 8. Parallel decrease in content of ergosterol (a) and reduction of ATPase activity (b) after near-UV irradiation in plasma membranes. After irradiation, ergosterol was extracted from one aliquot and ATPase activity was assayed in another. Each value represents the mean and standard error of results from three independent experiments.

the decrease in content of ergosterol. Dose-response curves for the decrease in ergosterol content were very similar to that for reduction of ATPase activity, indicating that photodecomposition of ergosterol in the membrane might be closely related to the reduction of the activity of membrane-bound ATPase brought about by near-UV irradiation.

\section{DISCUSSION}

The detection of a primary photochemical reaction is significant since this reaction represents the starting point of a photobiological phenomenon. The measurement of near-UV-induced absorbance changes in yeast cells and plasma membranes resulted in a decrease over a broad band with peaks at 272, 282 and $295 \mathrm{~nm}$ and a shoulder at $265 \mathrm{~nm}$. It was evident that this decrease in absorption spectra resulted, specifically, from photochemical decomposition of ergosterol through a photochemical reaction dependent on oxygen. In addition, intracellular photosensitizers might not be involved in photodecomposition of ergosterol since the degree of absorbance change in reconstructed liposomes was comparable to that in plasma membranes.

It is well known that ergosterol is photoconverted to previtamin $\mathrm{D}_{2}$, tachysterol and lumisterol by UV irradiation at $254 \mathrm{~nm}$ in vitro followed by heat conversion to vitamin $\mathrm{D}_{2}$ (Havinga et al., 1960; Havinga, 1973; Braun et al., 1991). These compounds show absorption in the region $220-300 \mathrm{~nm}$, since conjugated double bonds originating from the 5,7-sterol skeleton were maintained in this reaction (Braun et al., 1991). We attempted identification of the photodegradation products of ergosterol by near-UV radiation in vivo but these intermediates were not detected by spectrophotometry, HPLC analysis or NMR (data not shown). However, ergosterol solubilized in SDS solution was photoconverted to previtamin $\mathrm{D}_{2}$ following near-UV irradiation (unpublished data). The decrease in absorption spectra would imply cleavage of the 5,7-diene structure in ergosterol progressing with the photochemical reaction, since the broad band with specific peaks in the absorption spectrum of ergosterol is generally dependent on conjugated double bonds in the 5,7-sterol skeleton. This finding suggested that the mode of cleavage in membranes proceeded by a reaction distinct from the reaction of photoisomerization to previtamin $\mathrm{D}_{2}$ in vitro as reported by Braun et al. (1991). However, there has been little investigation into the photodegradation product(s) of ergosterol after nearUV irradiation in vivo.

Ergosterol is one of the major membrane components and plays an important role in normal expression of membrane function in fungi. In practice, ergosterol affects the uptake of amino acids (Singh et al., 1979), ion transport (Wagner et al., 1980) and membrane-bound enzyme activity (Imbrie \& Murphy, 1982). In addition, ergosterol is remarkably more useful than other sterols in stabilization of the membrane (Prasad, 1985). The activity of membrane-bound ATPase was clearly reduced in parallel to the decomposition of ergosterol. These facts further verify that ergosterol significantly affects physiological function and physicochemical properties of the plasma membrane. We reported previously that inactivation of the cell, so-called repression of cell growth, and membrane function, e.g. active transport and its ability to act as a permeability barrier, decreased sigmoidally with increasing dosage of near-UV radiation (Arami et al., 1993). The doseresponse curve for these phenomena was not in agreement with that for photodecomposition of ergosterol. However, a minimum level of ergosterol (approx. $25 \%$ of normal content) is essential for yeast cell viability (Parks et al., 1987; Leber et al., 1995). Ergosterol content was maintained above this threshold level during the period of inactivation of the cell by near-UV under the conditions chosen from our experiments. Therefore, it is considered, based on these findings, that photodecomposition of ergosterol is a primary photochemical reaction and a trigger for inactivation of the cell and damage to membrane function following near-UV irradiation of fungi. 


\section{REFERENCES}

Allen, C. F. \& Good, P. (1971). Acyl lipids in photosynthetic systems. Methods Enzymol 23, 523-547.

Arami, S., Hada, H., Itadani, A., Yamashita, S., Hachiya, K., Kanayama, M. \& Tada, M. (1993). Damage of membrane function in the yeast Saccharomyces cerevisiae by near-UV irradiation. $S c i$ Rep Fac Agric Okayama Univ 82, 1-7.

Arnezeder, C., Koliander, W. \& Hampel, W. A. (1989). Rapid determination of ergosterol in yeast cells. Anal Chim Acta 225, 129-136.

Ascenzi, J. M. \& Jagger, J. (1979). Ultraviolet action spectrum $(238-405 \mathrm{~nm})$ for inhibition of glycine uptake in $E$. coli. Photochem Photobiol 30, 661-666.

Boyce, R. P. \& Howard-Flanders, P. (1964). Release of ultraviolet light induced thymine dimers from DNA in Escherichia coli K-12. Proc Natl Acad Sci USA 51, 293-300.

Braun, M., Fuß, W. \& Kompa, K. L. (1991). Improved photosynthesis of previtamin D by wavelengths of $280-300 \mathrm{~nm}$. Photochem Photobiol 61, 15-26.

Darszon, A., Vandenberg, C. A., Schonfeld, M., Ellisman, M. H., Spitzer, N. C. \& Montal, M. (1980). Reassembly of protein-lipid complexes into large bilayer vesicles: perspective for membrane reconstitution. Proc Natl Acad Sci USA 77, 239-243.

Fiske, C. H. \& Subbarow, Y. (1925). The colorimetric determination of phosphorus. J Biol Chem 66, 375-400.

Havinga, E. (1973). Vitamin D, example and challenge. Experientia 29, 1181-1316.

Havinga, E., Kock, R. J. \& Rappoldt, M. P. (1960). Photochemical interconversions of provitamin D, lumisterol, previtamin D and tachysterol. Tetrabedron 11, 276-284.

Imbrie, C. W. \& Murphy, T. M. (1982). UV-action spectrum (254-405 nm) for inhibition of a $\mathrm{K}^{+}$-stimulated ATPase from the plasma membrane of Rosa damascena. Photochem Photobiol 36, 537-542.

Ito, A. \& Ito, T. (1983). Possible involvement of membrane damage in the inactivation by broad-band near-UV radiation in Saccharomyces cerevisiae cells. Photochem Photobiol 37, $395-401$.

Jagger, J. (1981). Near-UV radiation effects on microorganisms. Photochem Photobiol 34, 761-768.
Leber, R., Zinser, E., Hrastnik, C., Paltauf, F. \& Daum, G. (1995). Export of steryl ester from lipid particles and release of free sterols in the yeast, Saccharomyces cerevisiae. Biochim Biophys Acta 1234, 119-126.

Parks, L. W., Lewis, T. A., Low, C. \& Haeckler, K. (1987). Fungal sterols. In The Metabolism, Structure and Function of Plant Lipids, pp. 57-61. Edited by P. K. Stumpf, J. B. Mudd \& W. D. Nes. New York: Plenum.

Piette, J., Merville-Louis, M.-P. \& Decuyper, J. (1986). Damage induced in nucleic acids by photosensitization. Photochem Photobiol 44, 793-802.

Prasad, R. (1985). Lipids in the structure and function of yeast membrane. Adv Lipid Res 21, 187-242.

Robb, F. T., Hauman, J. \& Peak, M. J. (1978). Similar spectra for the inactivation by monochromatic light of two distinct leucine transport systems in E. coli. Photochem Photobiol 27, 465-469.

Rosenstein, B. S. \& Ducore, J. M. (1983). Induction of DNA strand breaks in normal human fibroblasts exposed to monochromatic ultraviolet and visible wavelengths in the $240-546 \mathrm{~nm}$ range. Photochem Photobiol 38, 51-55.

Sharma, R. C. \& Jagger, J. (1981). Ultraviolet (254-405 nm) action spectrum and kinetics of alanine uptake in Escherichia coli B/R. Photochem Photobiol 33, 173-177.

Siegel, S. M. \& Corn, C. (1974). Thermal and ionic factors in the ultraviolet photolysis of plant cell membrane. Physiol Plant 31, 267-270.

Singh, M., Jayakumar, A. \& Prasad, R. (1979). The effect of altered ergosterol content on the transport of various amino acids in Candida albicans. Biochim Biophys Acta 555, 42-55.

Tada, M. \& Shiroishi, M. (1982). Mechanism of photoregulated carotenogenesis in Rhodotorula minuta. II. Aspects of photoregulative reaction. Plant Cell Physiol 23, 549-556.

Tyrrell, R. M. (1973). Induction of pyrimidine dimers in bacterial DNA by $365 \mathrm{~nm}$ radiation. Photochem Photobiol 17, 69-73.

Wagner, G., Geissler, G., Linhardt, R., Mollow, A. \& Vonhof, A. (1980). Light-dependent ion transport processes and photosensory transition in Halobacterium. Dev Plant Biol 4, 641-644.

Received 24 June 1996; revised 1 December 1996; accepted 16 December 1996. 